\title{
Effects of Intracerebroventricular Administration of Adrenoceptor-Agonists on the Regulation of Renal Water and Electrolytes Handling through Endocrine, Renal and Hemodynamic Function
}

\author{
Kozo Ota, Tokihisa Kimura, Masaru Shoji, Minoru \\ Inoue, Kazutoshi Sato, Masahiro Ohta, Tadasu \\ Yamamoto, Kazuo Tsunoda, KeIshi Abe* and KaorU \\ Yoshinaga \\ The Second Department of Internal Medicine, and \\ *Department of Clinical Biology and Hormonal \\ Regulation, Tohoku University School of Medicine, Sendai \\ 980
}

Ota, K., Kimura, T., Shoji, M., Inoue, M., Sato, K., Оhta, M., Yamamoto, T., Tsunoda, K., ABe, K. and Yoshinaga, K. Effects of Intracerebroventricular Administration of Adrenoceptor-Agonists on the Regulation of Renal Water and Electrolytes Handling through Endocrine, Renal and Hemodynamic Function. Tohoku J. Exp. Med., 1990, 162 (1), 27-39 — In order to assess the roles of central adrenoceptors in the release of atrial natriuretic peptide (ANP), aldosterone (ALD), vasopressin (AVP) and renin as well as in the regulation of renal and cardiovascular functions, either norepinephrine (NE; $0.07 \mu \mathrm{g} / \mathrm{kg} / \mathrm{min})$, guanabenz (GB ; $\alpha_{2}$-agonist $; 0.4 \mu \mathrm{g} / \mathrm{kg} / \mathrm{min}$ ), methoxamine (MET ; $\alpha_{1}$-agonist $; 0.4 \mu \mathrm{g} / \mathrm{kg} /$ $\mathrm{min}$ ), or isoproterenol (ISO; $\beta$-agonist; $0.07 \mu \mathrm{g} / \mathrm{kg} / \mathrm{min}$ ), dissolved in the artificial cerebrospinal fluid (ACSF), was intracerebroventricularly (i.c.v.) administered at a rate of $10 \mu \mathrm{l} / \mathrm{min}$ for $30 \mathrm{~min}$ in anesthetized dogs. In the control study, the drugs were omitted. NE decreased mean arterial pressure (MAP), urinary osmolality (Uosm) and plasma ALD and AVP concentrations, and increased urine flow (UF). GB increased UF and urinary $\mathrm{K}$ excretion without any changes in urinary $\mathrm{Na}$ excretion, but decreased plasma ALD and AVP, heart rate, and Uosm without changes in MAP. ISO decreased MAP and plasma ALD, and increased $\mathrm{Na}$ and $\mathrm{K}$ output, renal plasma flow and UF with decreased Uosm. MET and ACSF failed to affect any of these parameters. Glomerular filtration rate, plasma ANP concentration and renin activity did not change in any of the studies. The present results suggest that central $\alpha_{2}$ - and $\beta$-adrenoceptors may attenuate ALD

Received June 15, 1990 ; rerevision accepted for publication August 18, 1990.

Offprints requests : K. Ota, M.D., the Second Department of Internal Medicine, Tohoku University School of Medicine, 1-1 Seiryo-machi, Aobaku 980, Sendai, Japan. 
and/or AVP release without changes in ANP and renin release, and decrease blood pressure, thereby causing a diuresis and natriuresis._- vasopressin ; atrial natriuretic peptide; aldosterone ; renin ; blood pressure; renal function

It is well known that the afferent impulse arising from cardiopulmonary receptors and arterial baroreceptors elicited by a distortion of the body fluid and blood pressure, are integrated in the central nervous system, which may affect the sympathetic nervous outflow, renin-angiotensin-aldosterone system (RAAS), vasopressin (AVP) release and renal and cardiovascular function, thereby resulting in the restoration of the body fluid and blood pressure.

Indeed, the intracerebroventricular (i.c.v.) administration of norepinephrine has been reported to affect AVP and renin release and to exert natriuresis and diuresis (Morris et al. 1977 ; Beal and Bligh 1980 ; Kimura et al. 1981 ; Ganong et al. 1982 ; Brooks et al. 1986). Stimulation of central $\alpha_{2}$-adrenoceptors was found to elicit natriuresis and a fall in AVP and ACTH release as well as a fall in plasma renin activity (PRA) and blood pressure (Reid et al. 1975; Ganong et al. 1982 ; Kimura et al. 1984 ; Brooks et al. 1986 ; Koepke and DiBona 1986). Especially, clonidine, an $\alpha_{2}$ - agonist, given i.c.v has been reported to stimulate the release of atrial natriuretic peptide (ANP), thereby resulting in the natriuresis and diuresis in rats (Pan and Gutkowska 1988). On the other hand, central $\alpha_{1}$-adrenoceptors were shown to activate AVP release and to rise PRA and blood pressure (Ganong et al. 1982 ; Brooks et al. 1986; Leffler et al. 1987). Moreover, central $\beta$ adrenoceptors were documented to stimulate the efferent sympathetic nervous system (SNS) with subsequent antidiuresis and antinatriuresis and to increase PRA (Morris et al. 1977; Koepke et al. 1983; Koepke and DiBona 1985). These results suggest that the central SNS may participate in the body fluid regulation.

However, it remains to be unknown whether stimulation of either central $\alpha$ or $\beta$-adrenoreceptors affect ANP and aldosterone (ALD) as well as AVP release, thereby resulting in changes in renal water and electrolytes handling, and also whether the central stimulation of adrenoceptors affects the renal function.

In the present study, therefore, in order to clarify the role of the central SNS in the regulation of body fluid and blood pressure, i.c.v administration of norepinephrine, methoxamin, an $\alpha_{1}$-agonist, guanabenz, an $\alpha_{2}$-agonist, and isoproterenol, a $\beta$-agonist were carried out in anesthetized dogs, and plasma ANP, ALD, and AVP levels, PRA, blood presure, heart rate and renal water and electrolytes handling were determined.

\section{Materials and Methods}

Experiments were carried out in 30 female mongrel dogs weighing 7-11 kg. They were anesthetized with pentobarbital sodium $(30 \mathrm{mg} / \mathrm{kg}$, i.v.) and supplemental doses of anesthetic were given as needed. Tracheal intubation was performed to keep the airway open. Both femoral arteries and veins were cannulated for arterial pressure monitoring, periodic blood sampling, and infusion of solutions. Both ureters were exposed through an abdomi- 
nal incision and catheterized with PE-210 polyethylene tubing for collection of urine. The head of the animal was placed in a stereotaxic device (Narishige Instruments, Tokyo) and a 20-gauge needle was placed in the left lateral ventricle. Polyethylene tubing (PE 90) was attached to the needle to permit intracerebroventricular (i.c.v.) infusion. The correct placement of the tip of the icv needle was verified at the end of each experiment by an injection of indigo blue solution. A 19-gauge needle was inserted into the cisterna magna to collect the cerebrospinal fluid (CSF).

After the completion of surgery, i.v. infusion of $0.9 \% \mathrm{NaCl}$ was initiated at a rate of $0.05 \mathrm{ml} / \mathrm{kg} / \mathrm{min}$. A priming injection of paraminohippuric acid (PAH, $5 \mathrm{mg} / \mathrm{kg})$ and inulin (IN, $60 \mathrm{mg} / \mathrm{kg}$ ) dissolved in $1 \mathrm{ml} / \mathrm{kg}$ of $0.9 \% \mathrm{NaCl}$ was given i.v. at $60 \mathrm{~min}$ after the initiation of $0.9 \% \mathrm{NaCl}$, and followed by a maintenance infusion of $\mathrm{PAH}(0.15 \mathrm{mg} / \mathrm{kg} / \mathrm{min})$ and IN $(1.0 \mathrm{mg} / \mathrm{kg} / \mathrm{min})$ dissolved in saline at a rate of $0.05 \mathrm{ml} / \mathrm{kg} / \mathrm{min}$ until the end of experiments. Mean arterial pressure (MAP) and pulsatile pressure were continuosly monitored with strain gauge transducers (P23D, Statham Instruments, Oxnard, CA, USA) connected to a recorder (Matsushita Communication Ind., Yokohama). Heart rate (HR) was calculated from the recording of pulsatile pressure. Experiments were started at time $-30 \mathrm{~min}, 90 \mathrm{~min}$ after the initiation of PAH and IN infusion. A 30-min i.c.v. infusion was commenced by a microinfusion pump (Narishige Instruments, Tokyo) at a rate of $10 \mu \mathrm{l}$ / min at time zero after two control periods of 15 min.

Animals were divided into 5 groups each consisting of 6 . Artificial cerebrospinal fluid (ACSF in mM/liter: $\mathrm{NaCl} 126.6, \mathrm{KCl} 2.95, \mathrm{NaHCO}_{3} 26.2, \mathrm{Na}_{2} \mathrm{HCO}_{3} 26.2, \mathrm{NaH}_{2} \mathrm{PO}_{4} \cdot \mathrm{H}_{2} \mathrm{O}$ $4.78, \mathrm{CaCl}_{2} \cdot 2 \mathrm{H}_{2} \mathrm{O} 1.8, \mathrm{MgSO}_{4} \cdot 7 \mathrm{H}_{2} \mathrm{O} 0.41$, urea 3.33, and dextrose 3.61) alone was i.c.v. infused in the ACSF group. (-)-Norepinephrine bitartrate $(0.07 \mu \mathrm{g} / \mathrm{kg} / \mathrm{min}$; Sigma, St. Louis, MO, USA), guanabenz acetate (GB, $0.4 \mu \mathrm{g} / \mathrm{kg} / \mathrm{min}$; Nihon Shoji Co., Tokyo), methoxamine hydrochloride (MET, $0.4 \mu \mathrm{g} / \mathrm{kg} / \mathrm{min}$, Nihon Shinyaku Co., Tokyo) and (-)-isoproterenol bitartrate (ISO, $0.07 \mu \mathrm{g} / \mathrm{kg} / \mathrm{min}$; Sigma) dissolved in the ACSF were i.c.v. infused in NE, GB, MET and ISO groups, respectively. Urine samples were consecutively collected 6 times at $15 \mathrm{~min}$ intervals during time $-30 \mathrm{~min}$ through time $60 \mathrm{~min}$. Blood samples of $12 \mathrm{ml}$ each were taken at 15-min intervals at the midpoint of each urine collection period. Sampled blood was replaced by a simultaneous injection of an equal volume of $6 \%$ dextran in $0.9 \% \mathrm{NaCl}$. Plasma was separated by centrifugation at $4{ }^{\circ} \mathrm{C}$ for $15 \mathrm{~min}$. Immediately, $3 \mathrm{ml}$ of plasma was mixed with $3.6 \mathrm{ml}$ of $0.1 \mathrm{~N} \mathrm{HCl}$ and kept frozen at $-20^{\circ} \mathrm{C}$ until the assay for ANP and AVP. One $\mathrm{ml}$ and $0.1 \mathrm{ml}$ of plasma were stored frozen until the assay for PRA and ALD. CSF samples of $1 \mathrm{ml}$ each were collected at time -15 and $60 \mathrm{~min}$.

Plasma concentrations of ANP and AVP were determined by radioimmunoassay (RIA) after extraction with Sep-Pak $\mathrm{C}_{18}$ cartridges (Waters Associates, Milford, MA, USA) as described previously (Kimura et al. 1980, 1986; Ota et al. 1988). The recovery of ANP was $79.0 \pm 2.1 \%$, and the intra- and interassay coefficients were $8.5 \%$ and $9.3 \%$, respectively. The recovery of AVP was $79.7 \pm 5.0 \%$, and the intra- and interassay coefficients were $5.6 \%$ and $6.8 \%$, respectively. PRA and plasma ALD concentrations were measured by the RIA reported elsewhere (Abe et al. 1978). IN was measured by the anthrone method (Davidson and Sackner 1963), and PAH was determined by the procedure of Waugh and Beall (1974). Glomerular filtration rate (GFR) and renal plasma flow (RPF) were estimated by clearances of IN and PAH, which were calculated by standard formulas. Plasma, CSF and urine osmolalities were measured by freezing point depression (model 3D2, Advanced Instruments, Needham Heights, MA, USA). Plasma, CSF and urine sodium (Na) and potassium (K) were measured by flame photometry (Hitachi flame photometer, 205D).

Statistical analysis of the data was performed by an analysis of variance for repeated measurements on the same variable (Winer 1971). Statistically significant differences were isolated by the Dunnett's test (within group) and unpaired $t$-test (between groups). All results were expressed as means \pm s.E. The value obtained either during the 2 nd control period $(-15$ to $0 \mathrm{~min})$ for urine data or at the midpoint of the period $(-7.5 \mathrm{~min})$ for plasma 


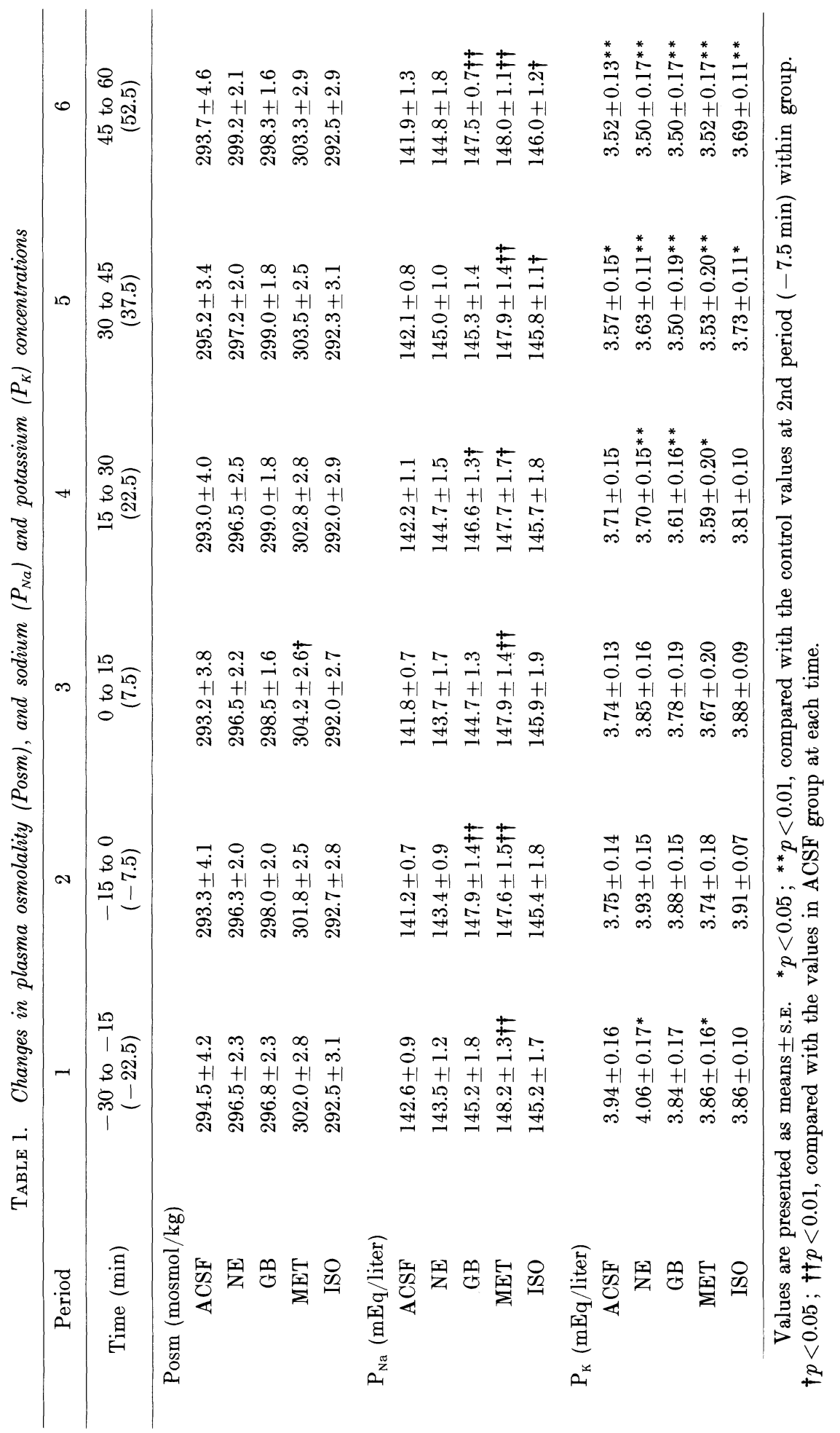


data was used as the control value for the respective analyses.

\section{Results}

Plasma $\mathrm{Na}$ and osmolality did not change significantly in the ACSF, NE, GB, MET, and ISO groups, respectively, throughout the experiments compared to each control value. The significant increase in plasma $\mathrm{Na}$ was noticed at the $2 \mathrm{nd}, 4$ th and 6th periods in the GB, at the whole periods in the MET, and at the last two periods in the ISO group compared to the comparable period in the ACSF group $(p<0.05)$. There was no difference in plasma $\mathrm{Na}$ between the NE and ACSF groups. No significant difference in plasma osmolality was noticed among the groups except for its significant rise at the 3rd period in the MET group $(p<0.05)$.

Plasma K significantly decreased at the 5th and 6th periods in the ACSF and ISO groups and at the 4th period and thereafter in the NE, GB and MET groups, accompanied by a significant rise at the initial period $(p<0.05)$ in the NE and MET groups. No difference was noticed among the groups (Table 1).

As shown in Fig. 1, plasma AVP decreased significantly at the 3rd period and thereafter in the NE group, and at the last two periods in the GB group, respectively, compared to each control value $(p<0.05)$, but did not change in the ACSF, MET, and ISO groups. The significant difference was noticed at the 4 th and 6 th periods between the NE and ACSF groups and at the 6th period between the GB

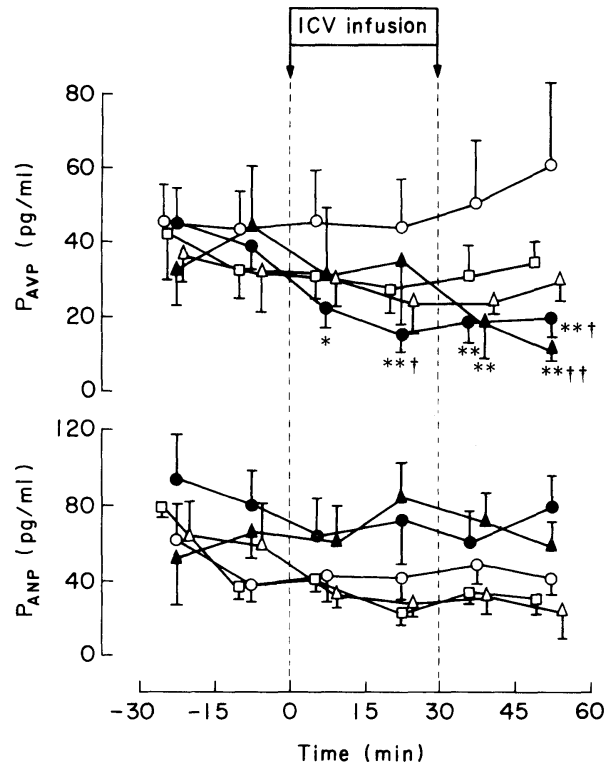

Fig. 1. Effects of icv infusion of either norepinephrine (NE, •), guanabenz (GB, $\Delta$ ), methoxamine (MET, $\square$ ), isoproterenol (ISO, $\triangle$ ) or artificial cerebrospinal fluid alone (ACSF, $\bigcirc)$ on plasma AVP and ANP concentrations. ${ }^{*} \mathrm{p}<$ $0.05 ;{ }^{* *} \mathrm{p}<0.01$ compared with the control values at $-7.5 \mathrm{~min}$ in each group. $\dagger p<0.05 ; \dagger \dagger p<0.01$ compared with the values in ACSF group at each time. 


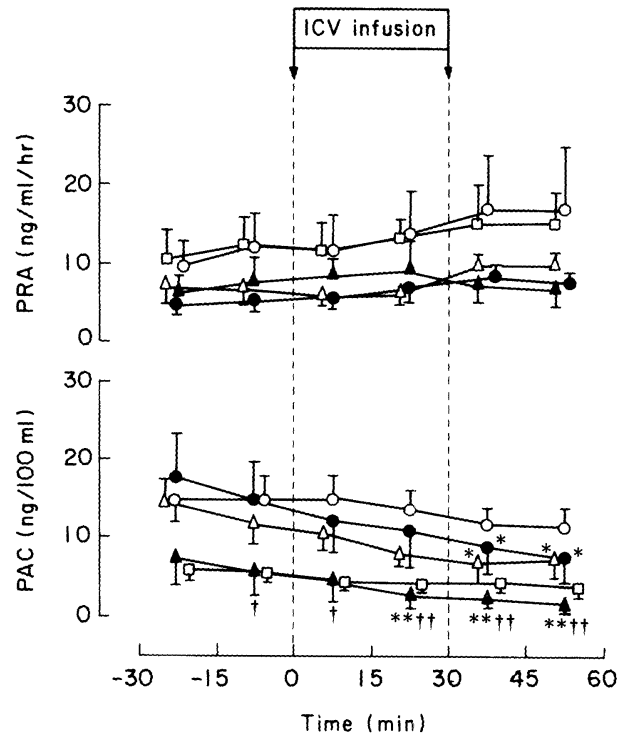

Fig. 2. Changes in plasma renin activity (PRA) and plasma aldosterone concentrations (PAC) during the i.c.v. infusion of adrenoceptor agonists or vehicle alone. Symbols are the same as ones in Fig. $1 .{ }^{*} p<0.05 ;{ }^{* *} p<0.01$ compared with the control values at $-7.5 \mathrm{~min}$ in each group. $\dagger p<0.05$, †† $p<0.01$ compared with the values in ACSF group at each time.

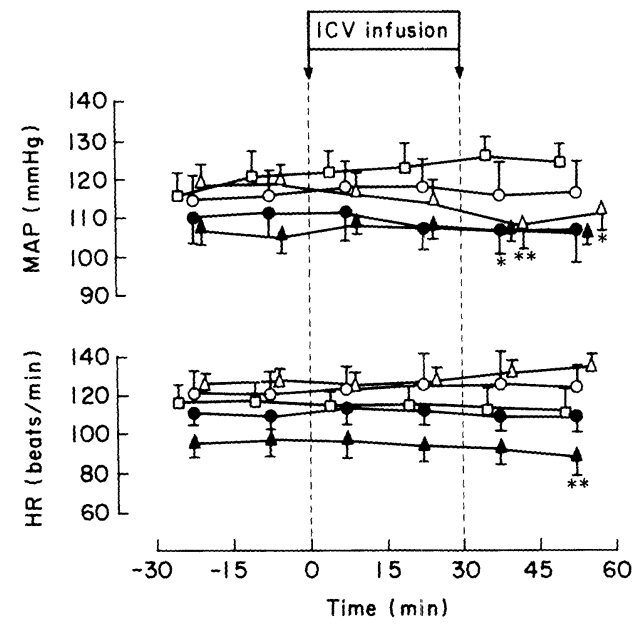

Fig. 3. Changes in mean arterial pressure (MAP) and heart rate (HR) during the i.c.v. infusion of adrenoceptor agonists or vehicle alone. Symbols are the same as ones in Fig. $1 .{ }^{*} p<0.05 ;{ }^{* *} p<0.01$ compared with the control values at $-7.5 \mathrm{~min}$ in each group. 
and ACSF groups, respectively $(p<0.05)$. Plasma ANP did not change during the whole experiment in all the groups and also no significant difference was noticed among the groups.

PRA did not change significantly during the whole periods in all the groups and there were no difference in it among the groups. Plasma ALD concentration decreased significantly at the 4 th period and thereafter in the GB, at the 5th and

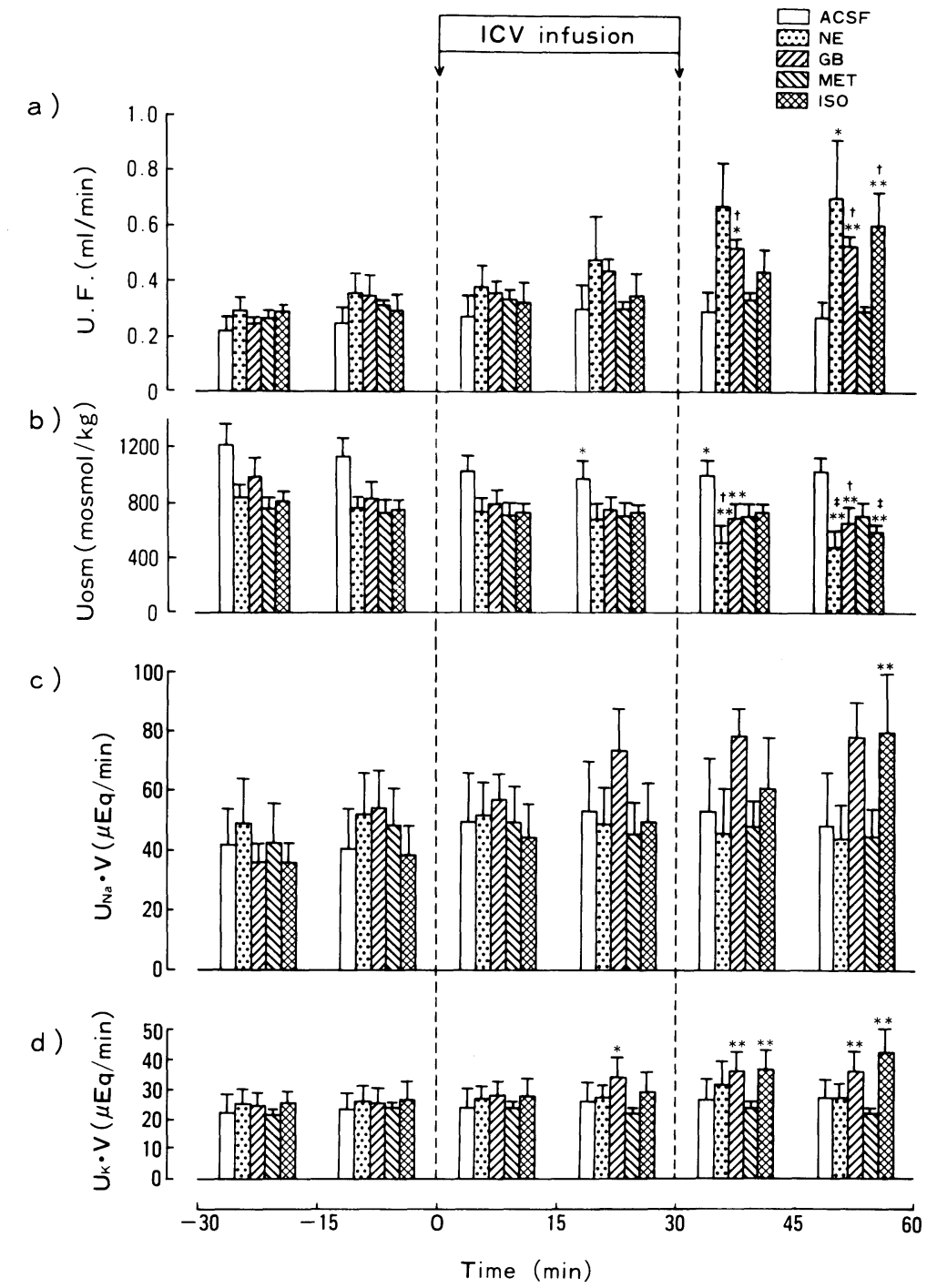

Fig. 4. Effects of i.c.v. infusion of either norepinephrine (ㅍ) methoxamine ( ), isoproterenol (ख), or artificial cerebrospinal fluid alone $(\square)$ on urine flow (U.F.) osmolality (Uosm), urinary sodium $\left(U_{\mathrm{Na}} \cdot \mathrm{V}\right)$ and potassium excretion $\left(\mathrm{U}_{\mathrm{K}} \cdot \mathrm{V}\right) .{ }^{*} p<0.05 ;{ }^{* *} p<0.01$ compared with the control values at -15 to 0 min in each group. $\dagger p<0.05 ; \dagger \dagger p<0.01$ compared with the values in ACSF group at each time. 
6th periods in the NE and ISO groups, respectively, as shown in Fig. 2. The significant difference was noticed at the whole periods except the 3rd period between the ACSF and GB groups $(p<0.05)$, but there were no differences among the other groups (Fig. 2).

MAP significantly decreased at the 5th period in the NE $(p<0.05)$, and the 5 th and 6 th periods in the ISO group $(p<0.05)$, but did not change in the other groups. There was no difference among the groups (Fig. 3). HR did not change in all the groups except the significant fall at the final period in the GB group $(p<$ 0.01 , Fig. 3).

Urine flow significantly increased at the final period in the NE and ISO groups and at the 5th and 6th periods in the GB group $(p<0.05)$. There were significant differences at the final period between the ACSF and ISO groups as well as at the 5th and 6th periods between the ACSF and NE groups $(p<0.05)$. Urinary osmolality significantly decreased at the 5 th and 6 th periods in the NE and GB $(p<0.01)$, at the 6th period in the ISO $(p<0.01)$, and at the 4 th and 5 th periods in the ACSF $(p<0.05)$ groups, respectively. The significant differences were noticed at the 6th period between the ACSF and either the GB or ISO group $(p<0.05)$ and at the 5th and 6th periods between the ACSF and NE groups $(p<$ 0.05 ) (Fig. 4a, b). Urinary Na excretion gradually increased in the ISO group and reached a significant level at the final period $(p<0.01)$. However, there were no changes in urinary $\mathrm{Na}$ excretion in the remaining groups, and no difference was noticed among the groups. Urinary $\mathrm{K}$ excretion significantly increased at the 4 th period and thereafter in the GB and at the 5th and 6th periods in the ISO group, respectively $(p<0.05)$ (Fig. $4 \mathrm{c}, \mathrm{d})$.

TABLE 2. Changes in glomerular filtration rate $(G F R)$ and renal plasma flow (RPF)

\begin{tabular}{ccccccc}
\hline Period & 1 & 2 & 3 & 4 & 5 & 6 \\
\hline Time (min) & -30 to -15 & -15 to 0 & 0 to 15 & 15 to 30 & 30 to 45 & 45 to 60 \\
\hline GFR (ml/min) & & & & & & \\
ACSF & $17.2 \pm 3.9$ & $19.3 \pm 4.7$ & $13.4 \pm 3.0$ & $11.7 \pm 2.2$ & $11.6 \pm 2.4$ & $11.1 \pm 1.5$ \\
NE & $15.3 \pm 3.8$ & $13.9 \pm 2.2$ & $12.5 \pm 1.6$ & $11.4 \pm 1.3$ & $10.6 \pm 1.1$ & $8.1 \pm 1.2$ \\
GB & $14.3 \pm 4.8$ & $15.5 \pm 5.5$ & $12.2 \pm 3.2$ & $12.8 \pm 2.0$ & $12.5 \pm 3.0$ & $11.3 \pm 2.3$ \\
MET & $9.0 \pm 2.8$ & $9.7 \pm 2.2$ & $10.2 \pm 2.2$ & $8.5 \pm 1.5$ & $8.7 \pm 1.2$ & $7.8 \pm 1.1$ \\
ISO & $12.1 \pm 2.9$ & $12.2 \pm 3.3$ & $10.7 \pm 2.5$ & $9.1 \pm 2.1$ & $10.1 \pm 1.6$ & $11.0 \pm 1.6$ \\
RPF (ml/min) & & & & & & \\
ACSF & $78.8 \pm 10.6$ & $87.3 \pm 13.9$ & $91.3 \pm 16.5$ & $79.5 \pm 9.7$ & $83.3 \pm 6.1$ & $94.4 \pm 7.0$ \\
NE & $89.3 \pm 16.0$ & $77.4 \pm 6.7$ & $73.8 \pm 9.2$ & $78.1 \pm 8.9$ & $79.3 \pm 8.2$ & $68.0 \pm 6.7$ \\
GB & $89.1 \pm 20.5$ & $79.3 \pm 18.3$ & $88.5 \pm 20.1$ & $97.0 \pm 28.9$ & $103.0 \pm 29.6$ & $95.0 \pm 26.7$ \\
MET & $86.4 \pm 29.9$ & $87.1 \pm 25.6$ & $83.5 \pm 25.2$ & $81.0 \pm 24.6$ & $85.8 \pm 23.9$ & $83.9 \pm 26.3$ \\
ISO & $69.4 \pm 23.6$ & $71.7 \pm 24.8$ & $71.5 \pm 19.7$ & $78.6 \pm 22.4$ & $103.8 \pm 25.1 *$ & $92.2 \pm 22.8$ \\
\hline
\end{tabular}

Values are means \pm S.E.. ${ }^{*} p<0.05$ compared to the value at 2 nd period. 
TABLE 3. Changes in cerebrospinal fluid osmolality (CSFosm) sodium (CSF $\left.{ }_{\mathrm{Na}}\right)$ and potassium $\left(C S F_{K}\right)$ concentrations

\begin{tabular}{ccc}
\hline & \multicolumn{2}{c}{ Time (min) } \\
\cline { 2 - 3 } & -15 & 60 \\
\hline CSFosm (mosmol/kg) & $295.5 \pm 3.0$ & $298.0 \pm 4.0$ \\
ACSF & $297.8 \pm 1.3$ & $303.7 \pm 1.7$ \\
NE & $304.3 \pm 3.7$ & $302.8 \pm 1.9$ \\
GB & $304.0 \pm 2.1$ & $307.8 \pm 2.5$ \\
MET & $293.0 \pm 2.9$ & $297.2 \pm 3.7$ \\
ISO & & \\
$\operatorname{CSF}_{\text {Na }}(\mathrm{mEq} /$ liter $)$ & $144.8 \pm 2.2$ & $145.5 \pm 2.6$ \\
$\mathrm{ACSF}$ & $148.5 \pm 1.2$ & $149.8 \pm 1.0$ \\
$\mathrm{NE}$ & $151.0 \pm 1.6$ & $150.6 \pm 1.6$ \\
$\mathrm{~GB}$ & $152.7 \pm 1.5$ & $154.7 \pm 1.9$ \\
$\mathrm{MET}$ & $147.6 \pm 2.3$ & $148.9 \pm 2.7$ \\
ISO & & \\
$\mathrm{ACSF}$ & $2.42 \pm 0.12$ & $2.52 \pm 0.10$ \\
$\mathrm{NE}$ & $2.18 \pm 0.10$ & $2.60 \pm 0.03$ \\
GB & $2.77 \pm 0.21$ & $2.62 \pm 0.11$ \\
$\mathrm{MET}$ & $2.31 \pm 0.17$ & $2.56 \pm 0.06$ \\
$\mathrm{ISO}$ & $2.11 \pm 0.19$ & $2.55 \pm 0.08$ \\
\hline
\end{tabular}

Values are means \pm s.E..

No GFR changed through the whole experiments in any groups and among all the groups. RPF also did not change during the whole periods in any groups except for a significant rise at the 5th period in the ISO group (Table 2). Osmolality and $\mathrm{Na}$ and $\mathrm{K}$ concentrations in the CSF did not alter before and after the experiments in any of the groups and no difference was noticed among the groups (Table 3 ).

\section{Discussion}

The present study obviously showed that ICV administration of NE and GB brought about a fall in plasma AVP and ALD without affecting plasma ANP and $\mathrm{PRA}$ and produced a rise in urine volume with decreased urine osmolality. NE and GB had no influence on the urinary $\mathrm{Na}$ excretion, but the latter enhanced urinary $\mathrm{K}$ excretion. ICV NE decreased blood pressure without any change in $\mathrm{HR}$, but GB slightly depressed HR, without any changes in blood pressure. ISO given centrally had no effect on plasma AVP, ANP, and PRA, but decreased plasma ALD. Moreover, ISO elicited a diuresis, natriuresis, kaliuresis with a fall in blood pressure. MET had no effect on the release of these hormones, blood 
pressure and renal and water electrolytes handling.

These results clearly showed that central $\alpha_{2}$-adrenoceptors might act to suppress AVP and ALD release with a subsequent diuresis, but not to affect renin and ANP release and blood pressure. However, central $\alpha_{1}$-adrenoceptors had no effect on the release of these hormones and cardiovascular and renal function. On the other hand, central $\beta$-adrenoceptors might depress ALD release without influencing AVP and ANP release and PRA, and produce the natriuresis, kaliuresis and a fall in blood pressure. Furthermore, the simultaneous stimulation of these receptors by NE produced a dominant effect of $\alpha_{2}$-adrenoceptors on AVP and ALD release and on diuresis, and that of $\beta$-adrenoceptors on the fall in blood pressure.

These results reconfirmed the previously reported concept which the central stimulation of $\alpha_{2}$-adrenoceptor induced by clonidine and NE suppressed AVP release and decreased blood pressure, except for the effect of GB on blood pressure, in morphine-urethane-chloralose anesthetized dogs (Kimura et al. 1981). The exact reasons for the absence of GB-mediated decreases in blood pressure were not clear from the present study, but the following explanation may be feasible. Since the dose of pentobarbital used in the present study is known to potentiate the relative activity of the SNS (Higuchi and Asakawa 1983), the drug may attenuate the capability of $\alpha_{2}$-adrenoceptors decreasing blood pressure in the present study. In addition, differences between clonidine and GB in the pharmacological action other than their $\alpha_{2}$-agonistic effects may bring about the different responses in blood pressure. Indeed, BHT993, a specific $\alpha_{2}$-agonist, was reported to suppress AVP release in a similar manner to clonidine, but had no effect on blood pressure (Brooks et al. 1986).

In the present study, stimulation of the central adrenoceptors have no effect on ANP release despite an increase in urine volume. Indeed, the increases in plasma AVP and blood pressure which have been reported to enhance ANP release (Manning et al. 1985; Inoue et al. 1988), were not noticed in the present study, but rather decreased. However, Pan and Gutkowska (1988) have recently shown that clonidine, an $\alpha_{2}$-agonist similar to GB, given ICV, increased ANP release via the opioid neurons, thereby resulting in an increase in urine volume and urinary $\mathrm{Na}$ excretion in conscious rats. We do not know the exact reasons for the difference between our results and theirs from the present study, but the structural differences between clonidine and GB as well as the differences in species and experimental protocols might be explainable of the absence of ANP response in the present study.

It has been reported that central administration of $\mathrm{NE}$ and clonidine produced a diuresis and/or natriuresis in rats, dogs and sheeps (Arruda Camargo et al. 1976 ; Morris et al. 1977 ; Beal and Bligh 1980 ; Pan and Gutkowska 1988), In the present study, urinary electrolites excretion did not change except for the GB-induced kaliuresis, but NE and GB produced a diuresis with a fall in urinary 
osmolality. Therefore, a fall in plasma AVP after NE and GB may be compatible with the diuresis, but decreased plasma ALD after GB may not explain the rise in urinary $\mathrm{K}$ excretion. In general, the increased $\mathrm{Na}$ load to the distal tubules has been reported to enhance $\mathrm{K}$ excretion in exchange of $\mathrm{Na}$, regardless of a quantity of ALD release (Rose 1984). In the present study, similarly, GB given i.c.v. might act to increase a $\mathrm{Na}$ load to the distal tubules, resulting in an increase in $\mathrm{K}$ excretion in exchange of $\mathrm{Na}$. Indeed, a previous report has suggested that central $\alpha_{2}$-adrenoceptors attenuated the renal sympathetic outflow with a subsequent fall in $\mathrm{Na}$ reabsorption in the proximal tubules (Koepke and DiBona 1986). However, one may argue against this concept, citing no attenuation of PRA in the present study, but the release of renin is also known to be attenuated by a rise in plasma AVP besides the decreased sympathetic nervous activity (Reid 1985). Therefore, the possibility is not ruled out that a fall in plasma AVP enhanced renin release, cancelling out a fall in renin release by the decreased sympathetic nervous activity.

To our knowledge, little is known about a fall in plasma ALD in response to $\mathrm{GB}$, ISO, and NE given centrally. In the present study, since PRA did not change throughout the experiments, PRA per se might not participate directly in the observed fall in plasma ALD. On the other hand, since it is well known that ACTH stimulates the synthesis of ALD as well as cortisol (Williams 1983), it is plausible that NE, GB, and ISO may act to suppress ACTH release and cause a fall in plasma ALD. Indeed, it has been reported that ICV NE and clonidine could attenuate cortisol release, suggestive of the suppression of ACTH release, in anesthetized dogs (Ganong et al. 1976, 1982). However, precise mechanisms by which these drugs give rise to a fall in ALD release remain to be clarified.

Activation of central $\beta$-adrenoceptors has been shown to increase the renal sympathetic outflow resulting in the antinatriuresis and antidiuresis (Arruda Camargo et al. 1976 ; Morris et al. 1977). Moreover, it has been shown that a $\beta$-antagonist given i.c.v. inhibited the stress-induced antidiuresis and antinatriuresis, indicative of central $\beta$-adrenoceptor-mediated antinatriuresis, in rats and dogs (Koepke et al. 1983 ; Koepke and DiBona 1985). On the other hand, ICV ISO has been reported to increase PRA accompanied by a fall in blood pressure in rats (Morris et al. 1976). Similarly, other studies also showed that ISO given ICV decreases blood pressure in rats and dogs (Kimura et al. 1981 ; Brooks et al. 1986). In the present study, indeed, ISO brought about a fall in blood pressure, but renal $\mathrm{Na}$ and $\mathrm{K}$ handling and renin release differed from the previously reported results (Arruda Camargo et al. 1976 ; Morris et al. 1976, 1977). However, if a decline in blood pressure is indicative of the decreased sympathetic nerve activity including the renal nerve, this effect may directly act to increase the renal blood flow thereby eliciting the natriuresis, kaliuresis and a fall in renin release. Indeed, in the present study, a rise in renal blood flow in response to ISO was accompanied by the natriuresis and kaliuresis. In contrast, a fall in blood 
pressure per se could counteract a reduction in renin release, thereby producing no changes in PRA in the present study. Indeed, it has been reported that a decrease in renin release after ICV clonidine is observed, only when renal perfusion pressure is maintained (Reid et al. 1975).

In conclusion, central $\alpha_{2}$-adrenoceptors acted to decrease plasma AVP and $\mathrm{ALD}$, accompanied by the diuresis and kaliuresis, but central $\alpha_{1}$-adrenoceptors had no effect on these hormones and renal water and electrolyte handling in anesthetized dogs. $\quad \beta$-adrenoceptors induced the natriuresis and kaliuresis and a fall in blood pressure. The activation of $\alpha$ - and $\beta$-adrenoceptors had no direct effect on ANP and renin release.

\section{Acknowledgments}

We thank Miss Michiko Okamoto for her help to measure PRA and ALD, and Miss Kumiko Hoshi for her secretarial assistance.

The generous gifts of guanabenz (Nihon Shoji Co.) and methoxamine (Nihon Shinyaku Co.) are gratefully acknowledged.

\section{References}

1) Abe, K., Irokawa, N., Yasujima, M., Seino, M., Chiba, S., Sakurai, Y., Yoshinaga, K. \& Saito, T. (1978) The kallikrein-kinin system and prostaglandins in the kidney. Circ. Res., 43, 254-260.

2) Arruda Camargo, L.A., Saad, W.A., Netto, C.R.S., Gentil, C.G., Antunes-Rodrigues, J. \& Covian, M.R. (1976) Effects of catecholamines injected into the septal area of the rat brain on natriuresis, kaliuresis and diuresis. Can. J. Physiol. Pharmacol., 54, 219-228.

3) Beal, A.M. \& Bligh, J. (1980) Diuretic effect of intraventricular and intravenous infusion of noradrenaline in conscious sheep. Q. J. Exp. Physiol., 65, 321-333.

4) Brooks, D.P., Share, L. \& Crofton, J.T. (1986) Central adrenergic control of vasopressin release. Neuroendocrinology, 42, 416-420.

5) Davidson, W.D. \& Sackner, M.A. (1963) Simplification of the anthrone method for the determination of inulin in clearance studies. J. Lab. Clin. Med., 62, 351-356.

6) Ganong, W.F., Kramer, N., Salmon, J., Reid, I.A., Lovinger, R., Scapagnini, U., Bo ryczka, A.T. \& Shackelford, R. (1976) Pharmacological evidence for inhibition of ACTH secretion by a central adrenergic system in the dog. Neuroscience, 1, 167-174.

7) Ganong, W.F., Chalett, J., Jones, H., Jr., Kaplan, S.L., Karteszi, M., Stith, R.D. \& Van De Kar, L.D. (1982) Further characterization of putative alpha-adrenergic receptors in brain that affect blood pressure and the secretion of $\mathrm{ACTH}, \mathrm{GH}$ and renin in dogs. Endocrinol. Exp. (Bratisl), 16, 191-205.

8) Higuchi, M. \& Asakawa, T. (1983) Effects of pentobarbital anesthesia on the plasma catecholamines and renin activity as reflected in the hemodynamic changes in dogs. Jpn. J. Pharmacol., 33, 209-217.

9) Inoue, M., Kimura, T., Ota, K., Iitake, K., Shoji, M., Sato, K., Ota, M. \& Yoshinaga, K. (1988) Effect of vasopressin on atrial natriuretic peptide release and renal function in dogs. Am. J. Physiol., 255 (Endocrinol. Metab. 18), E449-E455.

10) Kimura, T., Matsui, K., Ota, K. \& Yoshinaga, K. (1980) Radioimmunoassay of arginine vasopressin in human plasma and urine, a resin microcolumn method. Tohoku J. Exp. Med., 131, 37-46.

11) Kimura, T., Share, L., Wang, B.C. \& Crofton, J.T. (1981) The role of central adrenoceptors in the control of vasopressin release and blood pressure. Endocrinology, 
108, 1829-1836.

12) Kimura, T., Shoji, M., Iitake, K., Ota, K., Matsui, K. \& Yoshinaga, K. (1984) The role of central $\alpha_{1}$ - and $\alpha_{2}$-adrenoceptors in the regulation of vasopressin release and the cardiovascular system. Endocrinology, 114, 1426-1432.

13) Kimura, T., Abe, K., Ota, K., Omata, K., Shoji, M., Kudo, K., Matsui, K., Inoue, M., Yasujima, M. \& Yoshinaga, K. (1986) Effects of acute water load, hypertonic saline infusion, and furoseminde administration on atrial natriuretic peptide and vasopressin release in humans. J. Clin. Endocrinol. Metab., 62, 1003-1010.

14) Koepke, J.P. \& DiBona, G.F. (1985) Central $\beta$-adrenergic receptors mediate renal nerve activity during stress in conscious spontaneously hypertensive rats. Hypertension, 7, 350-356.

15) Koepke, J.P. \& DiBona, G.F. (1986) Central adrenergic receptor control of renal function in conscious hypertensive rats. Hypertension, 8, 133-141.

16) Koepke, J.P., Grignolo, A., Light, K.C. \& Obrist, P.A. (1983) Central beta adrenoceptor mediation of antinatriuretic response to behavioral stress in conscious dogs. $J$. Pharmacol. Exp. Ther., 227, 73-77.

17) Leffler, C.W., Busija, D.W., Share, L., Crofton, J.T., Brooks, D.P., Beasley, D.G., Green, R.S. \& Mirro, R. (1987) Adrenergic mediation of vasopressin secretion in newborn pigs. Am. J. Physiol., 253 (Regulatory Integrative Comp. Physiol. 22), R489-R493.

18) Manning, P.T., Schwartz, D., Katsube, N.C., Holmerg, S.W. \& Needleman, P. (1985) Vasopressin-stimulated release of atriopeptin : Endocrine antagonists in fluid homeostasis. Science, 229, 395-397.

19) Morris, M., Campbell, W.B. \& Pettinger, W.A. (1976) Renin and hemodynamic changes via central adrenergic, cholinergic, and sodium receptor mechanisms in conscious rats. Proc. Soc. Exp. Biol. Med., 151, 101-104.

20) Morris, M., McCann, S.M. \& Orias, R. (1977) Role of transmitters in mediating hypothalamic control of electrolyte excretion. Can. J. Physiol. Pharmacol., 55, 1143-1154.

21) Ota, K., Kimura, T., Matsui, K., Iitake, K., Shoji, M., Inoue, M. \& Yoshinaga, K. (1988) Effects of hemorrhage on vasopressin and met-enk releases in blood and cerebrospinal fluid in dogs. Am. J. Physiol., 255 (Regulatory Integrative Comp. Phsiol. 24), R731-R736.

22) Pan, L. \& Gutkowska, J. (1988) Is clonidine-induced diuresis mediated by atrial natriuretic factor? Endocrinology, 123, 1259-1263.

23) Reid, I.A. (1985) Inhibition of renin secretion by vasopressin: Mechanisms and physiological role. In : Vasopressin, edited by R.W. Schrier, Raven Press, New York, pp. 21-28.

24) Reid, I.A., MacDonald, D.M., Pachnis, B. \& Ganong, W.F. (1975) Studies concerning the mechanism of suppression of renin secretion by clonidine. $J$. Pharmacol. Exp. Ther., 192, 713-721.

25) Rose, B.D. (1984) Potassium homeostasis. In : Clinical Physiology of Acid-Base and Electrolyte Disorders. Chapter 13. McGraw-Hill, New York, pp. 248-268.

26) Waugh, W.H. \& Beall, P.T. (1974) Simplified measurement of p-aminohippurate and other arylamines in plasma and urine. Kidney Int., 5, 429-436.

27) Williams, G. H. (1983) Aldosterone. In: Renal Endocrinology, Chapter 7. Section 2. Nonrenal Hormones Acting on the Kidney, edited by M.J. Dunn; Williams \& Wilkins, Baltimore-London, pp. 205-223.

28) Winer, B.J. (1971) Statistical Principles in Experimental Design. McGraw-Hill, New York. 